\title{
Removal of a large jejunal laterally spreading tumor nongranular type by endoscopic submucosal dissection
}

Although endoscopic submucosal dissection (ESD) is widely performed for the resection of superficial gastrointestinal neoplasms, performing ESD for jejunal lesions is challenging because of the thin muscularis propria and inaccessibility or insufficient scope maneuverability around the lesion. Thus, few reports of ESD for jejunal lesions have been published [1]. Here, we report the case of a large jejunal laterally spreading tumor nongranular type (LST-NG) that was successfully treated with ESD ( $\vee$ Video 1 ).

A 62-year-old woman with familial adenomatous polyposis had a 50 -mm LST located on the afferent loop of the jejunum after pyloric ring-preserving pancreaticoduodenectomy ( $\triangleright$ Fig.1 a,b). Surgery was expected to be difficult because of multiple previous abdominal surgeries. Therefore, in order to reduce the risk of local recurrence associated with piecemeal resection, we chose ESD for en bloc resection.

ESD was performed using a gastroscope and ESD knives (DualKnife J and HookKnife J; Olympus, Tokyo, Japan). As the approach to the lesion faced the vertical direction, the HookKnife J was used for careful dissection ( Fig.1 c, d), and the clip-with-line method [2] was used for countertraction-facilitated resection ( $\triangleright$ Fig.1e). En bloc resection was achieved without any adverse events ( $\triangleright$ Fig.1f,g). The large mucosal defect was completely closed using endoloop and endoclips to prevent delayed bleeding and perforation ( $\mathbf{F i g} \mathbf{1} \mathbf{h}$ ). Histopathological findings revealed an adenoma ( $\mathbf{F i g} \cdot \mathbf{2}$ ). Follow-up esophagogastroduodenoscopy performed 3 months after ESD showed no evidence of local recurrence ( $\triangleright$ Fig. $1 \mathbf{i})$.
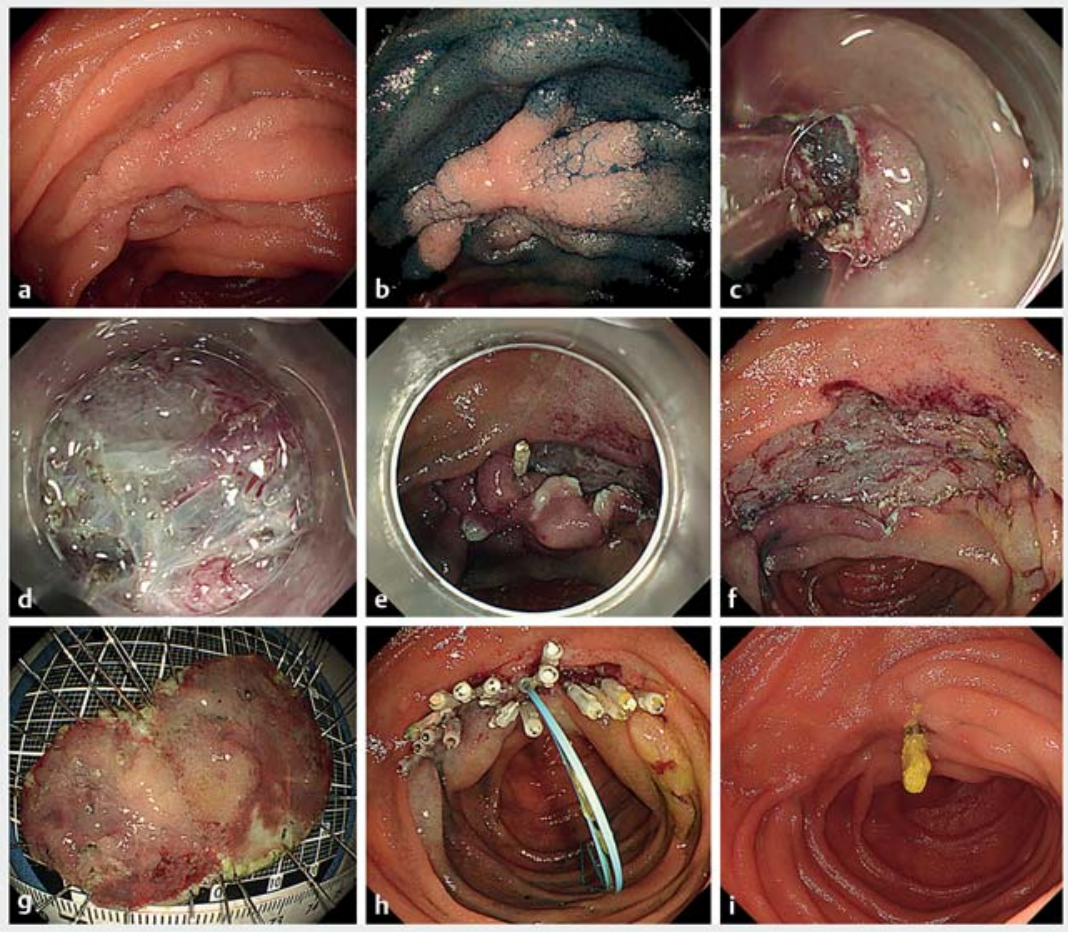

- Fig. 1 Endoscopic images showing a laterally spreading tumor in the proximal jejunum after pyloric ring-preserving pancreaticoduodenectomy. a In white light. b In chromoendoscopy using indigo carmine. c Mucosal incision. d Submucosal dissection. e Clip-with-line method to provide countertraction. $\mathbf{f}$ Large mucosal defect. $\mathbf{g}$ The resected specimen in white light. $\mathbf{h}$ Endoscopic closure using endoloop and endoclips. i Follow-up endoscopy 3 months after endoscopic submucosal dissection.

Although the indications for ESD of the jejunum have not been determined, the European Society of Gastrointestinal Endoscopy guidelines recommend that large LST-NG in the colon be treated with ESD [3]. In our case, ESD of the LST-NG in the jejunum was performed following the guidelines for ESD of LST-NG in the colon, and the clip-with-line method and HookKnife J were effective in this difficult situation.

Endoscopy_UCTN_Code_CCL_1AB_2AZ_3AB

\section{Competing interests}

Toshio Uraoka has received lecture fees from Olympus Co.

The authors

Kengo Kasuga, Toshio Uraoka, Takashi Negishi, Keigo Sato, Hirohito Tanaka, Hiroko Hosaka, Shiko Kuribayashi

Department of Gastroenterology and Hepatology, Gunma University Graduate School of Medicine, Maebashi, Japan 


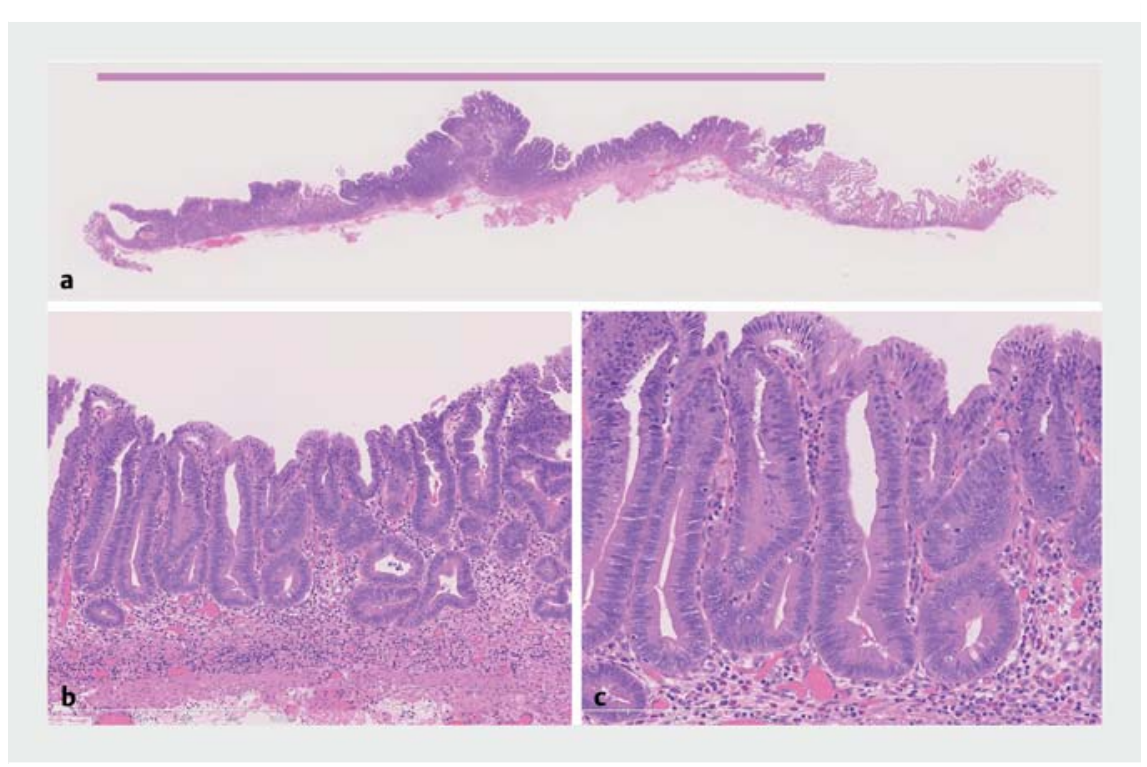

- Fig. 2 Histological examination of the resected specimen using hematoxylin and eosin stain. a The distribution of the lesion. Pink lines indicate low grade adenoma. $\mathbf{b}$ Low power magnified area of adenoma showing tubular growth. $\mathbf{c}$ High power magnified area of adenoma showing columnar cells with basal elongated nuclei.

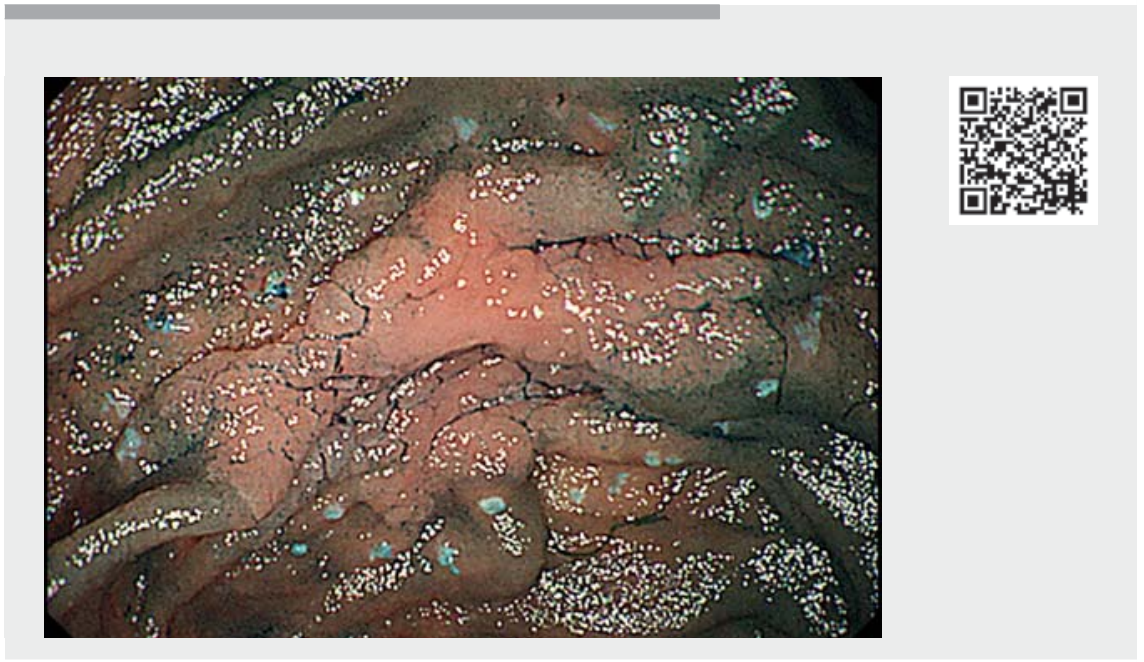

Video 1 Endoscopic submucosal dissection for a large jejunal lesion.
Corresponding author

\section{Toshio Uraoka, MD}

Department of Gastroenterology and Hepatology, Gunma University Graduate School of Medicine, 3-39-22 Showa-machi, Maebashi 371-8514, Japan uraoka@gunma-u.ac.jp toshi_urao@yahoo.co.jp

\section{References}

[1] lida M, Sakamoto H, Miura Y et al. Jejunal endoscopic submucosal dissection is feasible using the pocket-creation method and balloon-assisted endoscopy. Endoscopy 2018; 50: 931-932

[2] Oyama T. Counter traction makes endoscopic submucosal dissection easier. Clin Endosc 2012; 45: 375-378

[3] Pimentel-Nunes P, Dinis-Ribeiro M, Ponchon $T$ et al. Endoscopic submucosal dissection: European Society of Gastrointestinal Endoscopy (ESGE) Guideline. Endoscopy 2015; 47: 829-854

\section{Bibliography}

Endoscopy 2022; 54: E542-E543

DOI 10.1055/a-1675-1897

ISSN 0013-726X

published online 15.11.2021

(c) 2021. Thieme. All rights reserved.

Georg Thieme Verlag KG, Rüdigerstraße 14,

70469 Stuttgart, Germany

\section{ENDOSCOPY E-VIDEOS}

https://eref.thieme.de/e-videos

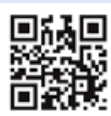

Endoscopy E-Videos is an open access online section, reporting on interesting cases and new techniques in gastroenterological endoscopy. All papers include a high quality video and all contributions are freely accessible online. Processing charges apply (currently EUR 375), discounts and wavers acc. to HINARI are available.

This section has its own submission website at https://mc.manuscriptcentral.com/e-videos 